\title{
The Effect of Postoperative Intravesical BCG and Mitomycin C Therapy on Recurrence of Non-Muscle Invasive Bladder Cancer
}

\author{
Kursad Zengin ${ }^{\mathrm{a}, \mathrm{f}}$, Serhat Tanik ${ }^{\mathrm{a}}$, Nevzat Can Sener ${ }^{\mathrm{b}}$, Ismail Nalbant ${ }^{\mathrm{c}}$, Musa Ekici ${ }^{\mathrm{d}}$, \\ Ibrahim Halil Bozkurt ${ }^{\mathrm{e}}$, Orhan Yigitbasi ${ }^{\mathrm{d}}$, Memduh Nurettin Sertcelik ${ }^{\mathrm{d}}$
}

\begin{abstract}
Background: We aimed to evaluate the efficacy of two mostly used intravesical agents, bacillus Calmette-Guerin (BCG) and mitomycin $\mathrm{C}$ (MMC), for tumor recurrence in non-muscle invasive bladder cancer.
\end{abstract}

Methods: Between January 2002 and April 2008, we performed TUR-BT on 127 patients whose pathology results were superficial bladder cancer. Patient files are examined retrospectively. Fortyone patients were treated with intravesical BCG once a week for 6 weeks, and then monthly up to 1 year from 14th day postoperatively. Twenty-six patients were treated with intravesical MMC, from first $6 \mathrm{~h}$ postoperatively and once a week for 8 weeks.

Results: There was no statistically significant difference between groups for age, gender, number of tumors, tumor size, and pathological staging $(\mathrm{P}=0.354, \mathrm{P}=0.315, \mathrm{P}=0.457, \mathrm{P}=0.302$, and $\mathrm{P}=$ 0.692 , respectively). In BCG group, $13(31.7 \%)$ patients recurred. For MMC group, recurrence was seen in $9(34.6 \%)$ patients. One and three years disease free survival rates were $92.7 \%$ and $75.7 \%$ in BCG group, and $76.9 \%$ and $62.9 \%$ in MMC group. In BCG group, estimated recurrence-free survival was 58.1 months, and it was 34.6 months for MMC group. Estimation difference among groups was

Manuscript accepted for publication October 28, 2013

${ }^{a}$ Department of Urology, Faculty of Medicine, Bozok University, Yozgat, Turkey

${ }^{\mathrm{b}}$ Department of Urology, Numune Education and Research Hospital, Ministry of Health, Adana, Turkey

${ }^{c}$ Department of Urology, Yenimahalle State Hospital, Ministry of Health, Ankara, Turkey

${ }^{\mathrm{d}}$ Department of Urology, Diskapi Education and Research Hospital, Ministry of Health, Ankara, Turkey

${ }^{\mathrm{e}}$ Department of Urology, Bozyaka Education and Research Hospital, Ministry of Health, Izmir, Turkey

${ }^{f}$ Corresponding author: Kursad Zengin, Bozok Universitesi Uygulama ve Arastirma Hastanesi, Uroloji Ana Bilim Dali, Yozgat, Turkey.

Email: kursadzengin@gmail.com

doi: http://dx.doi.org/10.4021/wjnu128e statistically significant $(\mathrm{P}=0.017)$.

Conclusions: Intravesical adjuvant BCG maintenance therapy is more effective for tumor recurrence than intravesical MMC therapy.

Keywords: BCG; Bladder cancer; Mitomycin C

\section{Introduction}

Bladder cancer is one of the most common cancers in urological practice. Bladder cancer is three times more common in men than women. Ninety percent of all bladder cancers are transitional cell carcinomas [1]. At the time of diagnosis, $74 \%$ of all bladder carcinomas are superficial, $18 \%$ of them are locally advanced and $8 \%$ metastatic. Even though most bladder carcinomas are non-muscle invasive (Ta, T1), there is a $30-80 \%$ risk of recurrence after transurethral resection of bladder tumor (TUR-BT) alone. In addition to that, 10-15\% of all patients will progress to muscle invasive disease [2].

The most important factors of tumor recurrence and progression of non-muscle invasive bladder carcinomas (NMIBC) are pathological stage, tumor grade, concomitant carcinoma in situ (CIS), tumor diameter, number of tumors, and previous recurrences [3]. The treatment of NMIBC involves intracavitary immunotherapy with bacillus CalmetteGuerin (BCG) and chemotherapy with mitomycin C (MMC), epirubicin, doxorubicin as well as TUR-BT. The main reason of this treatment regime is to decrease recurrence and progression rates [4]. For low-grade Ta tumors, 3-year recurrence rates are over $50-70 \%$ and progression rates are over $5 \%$ [5]. On the other hand, for the same period, recurrence and progression rates of $\mathrm{T} 1$ tumors are as high as $80 \%$ and $50 \%$ [6]. The main reason of intracavitary treatment regime is to decrease these rates and to treat residual tumors following TUR-BT [7].

Urology guidelines on NMIBC cannot advice an optimal regime for intracavitary treatment [8]. For this reason, we analyzed our patients who received intracavitary treatment and compared them according to their recurrence rates to help determine the optimal treatment. 
Table 1. Pathological Staging Among Groups

\begin{tabular}{llll}
\hline Stage & BCG $(\mathbf{n}=\mathbf{4 1})$ & MMC (n= 26) & Total \\
\hline $\mathrm{TaG} 1$ & $17(41.5 \%)$ & $11(42.3 \%)$ & $28(41.8 \%)$ \\
$\mathrm{TaG} 2$ & $2(4.9 \%)$ & $4(15.4 \%)$ & $6(9.0 \%)$ \\
$\mathrm{TaG3}$ & $1(2.4 \%)$ & $1(3.8 \%)$ & $2(3.0 \%)$ \\
$\mathrm{T} 1 \mathrm{G} 2$ & $7(17.1 \%)$ & $2(7.7 \%)$ & $9(13.4 \%)$ \\
$\mathrm{T} 1 \mathrm{G} 3$ & $14(34.1 \%)$ & $8(30.8 \%)$ & $22(32.8 \%)$ \\
& $41(100 \%)$ & $26(100 \%)$ & $67(100 \%)$ \\
\hline
\end{tabular}

\section{Materials and Methods}

Medical reports of 127 patients receiving intravesical treatment for NMIBC between January 2002 and April 2008 were retrospectively analyzed. Of these patients, 41 of them had received 1 year of BCG, and 26 had received 8 weeks of MMC instillations. Patients not receiving any intravesical treatment were excluded from the study. Patients receiving MMC and BCG were grouped as group 1 and group 2, respectively.

Preoperative cystoscopy was performed to all patients. Tumor location, size, type, number of tumors, and concomitant CIS (if any) were noted. Superficial and deep tissues during resection were collected separately, and transurethral biopsies were performed in suspected areas.

After TUR-BT, 26 patients received $40 \mathrm{mg}$ of MMC in the first $6 \mathrm{~h}$ following the operation. Those patients received 8 weeks of additional MMC treatment.

Forty-one patients received 1-year BCG instillations. For BCG treatment, patients were received $81 \mathrm{mg}$ of Connaught BCG intravesically. Those patients received weekly BCG for 6 weeks and monthly for 1 year.

Patients were called for cystoscopic evaluations in every 3 months for the first year, in every 6 months in second year, and annually for next years.

Groups were compared according to gender, number of tumors, tumor size, and stage. TUR-BT was performed on patients suffering from recurrences. Months to recurrence were noted. Groups were compared according to time to recurrence.

Statistical analysis was performed using SPSS for Windows 11.5. Groups were compared using Student's t test. Nominal parameters were evaluated by Pearson's Chi-square test and Fisher's exact test. Kaplan-Maier survival analysis was carried out using log-rank method. $\mathrm{P}<0.05$ was consid- ered statistically significant.

\section{Results}

While the age in BCG group ranges between 36 and 85 years (mean $59.83 \pm 10.59$ years), in MMC group, it ranges between 35 and 76 years $(57.42 \pm 9.73$ years). There was not any statistically significant difference for age (P $=0.354)$. In BCG group, there were 36 men and 5 women (87.8\%/12.2\%); in MMC group, there were 20 men and 6 women $(76.9 \% / 23.1 \%)(\mathrm{P}=0.315)$.

When compared according to number of tumors, there was no significant difference between the groups $(\mathrm{P}=0.457)$. Tumor size in BCG group was a mean of $3.30 \pm 1.54 \mathrm{~cm}(1$ $-7 \mathrm{~cm}$ ), and $2.80 \pm 1.00 \mathrm{~cm}$ in MMC group. Tumor size was also not different among groups $(\mathrm{P}=0.302)$.

Grades and stages were classified as TaG1, TaG2, TaG3, T1G1, T1G2, and T1G3 for both groups. No T1G1 was confronted in pathology reports. For pathological staging, there was not any statistically significant difference among groups $(\mathrm{P}=0.692)$. These stages are shown in Table 1 .

Duration of follow-up was 12 - 83 months (mean 38.22 \pm 20.43 months). One and three years disease free survival rates were $92.7 \%$ and $75.7 \%$ in BCG group, and $76.9 \%$ and $62.9 \%$ in MMC group. For BCG group, estimated recurrence-free survival was 58.1 months ( $95 \%$ confidence ratio: 46.8-69.3), and for MMC group, estimated recurrence-free survival was 34.6 months (95\% confidence ratio: $26.5-42.8$ ). Estimation difference among groups was statistically significant $(\mathrm{P}=0.017)$. Recurrence-free survivals are summarized in Table 2.

Thirteen patients (31.7\%) in BCG group and 9 patients in MMC group (34.6\%) had recurred. Among recurrent patients, groups were compared according to number of 
Table 2. Recurrence-Free Survivals Among Groups

\begin{tabular}{llll}
\hline One year recurrence-free & $92.7 \%$ & $76.9 \%$ & $86.6 \%$ \\
Two years recurrence-free & $82.3 \%$ & $64.9 \%$ & $75.0 \%$ \\
Three years recurrence-free & $75.7 \%$ & $62.9 \%$ & $69.2 \%$ \\
Estimated recurrence-free & $58.1(46.8-69.3)$ & $34.6(26.5-42.8)$ & $51.9(41.8-62.0)$ \\
\hline
\end{tabular}

tumors. BCG group had $10(76.9 \%)$ patients with solitary tumor, $2(15.4 \%)$ patients with two tumors and one patient $(7.7 \%)$ with three tumors. Similar to that, in MMC group, 8 $(88.9 \%)$ patients had solitary tumor and 1 patient $(11.1 \%)$ had three tumors. When number of tumors was compared among groups, there was no statistically significant difference observed $(P=0.695)$.

In recurrent cases, tumor size was compared. In BCG and MMC groups, tumor size was $2-5 \mathrm{~cm}$ (mean $3.2 \pm 1.2$ $\mathrm{cm})$, and $1-4 \mathrm{~cm}$ (mean $2.3 \pm 1.2 \mathrm{~cm}$ ), respectively $(\mathrm{P}=$ $0.110)$. When these cases were compared according to pathologies, there was no statistically significant difference observed $(\mathrm{P}=0.647)$ (Table 3$)$.

\section{Discussion}

Standard treatment for NMIBC is TUR-BT and adjuvant chemo- or immuno-treatment for risk groups [9]. Even with these treatments, there is $30-85 \%$ recurrence risk and $10-15 \%$ progression risk [2]. In 2006, European Organization for Research and Treatment of Cancer (EORTC) stated number of tumors, tumor size, previous recurrence duration, $\mathrm{T}$ stage, presence of CIS, and tumor grade as risk factors for tumor recurrence and progression. For a patient, recurrence and progression scores and probabilities can be calculated with diagrams [3]. Because of higher recurrence and progression rates among tumors, adjuvant treatments were introduced to standard treatments. BCG, MMC, epirubicin, thiotepa, doxorubicin, and gemcitabine are more commonly used as intravesical agents [10]. Ideal intravesical agent should be inexpensive, with minimal toxicity, and may be used as single dose. There is no agent to fulfill all these requirements.

Brosman compared the advantage on TUR-BT and adjuvant MMC to TUR-BT alone. It was to first one-center study and there was $30 \%$ advantage in adjuvant therapy group [11]. Boccon-Gibod et al followed $47 \mathrm{~T} 1$ patients, who received BCG treatment between one or three sessions for 14 to 60 months. In BCG group, they found 36\% recurrence and $21 \%$ progression risk, whereas in the control group, there was $90 \%$ recurrence and $34 \%$ progression risk [12]. Pansadoro et al reported a study which they applied at least 6 weeks of BCG treatment to 50 patients with high grade T1 disease. They reported $28 \%$ recurrence and $12 \%$ progression [13]. In our study, we presented the results of 1-year BCG treatment weekly for 6 weeks and monthly after that for 1 year. For a period of 3 years, we have $75.7 \%$ recurrence-free rate and it matches the literature for BCG group.

For the treatment of patients with non-muscle invasive bladder tumors, immediate single-dose chemotherapy is recommended for all patients after TUR-BT. Two EORTC trials compared immediate $(<24 \mathrm{~h})$ with late (between 7 and 15 days) instillations of $30 \mathrm{mg} \mathrm{MMC}$ and $50 \mathrm{mg}$ doxorubicin.

Table 3. Pathological Stages of Recurrent Cases Among Groups

\begin{tabular}{llll}
\hline Pathology & BCG $(\mathbf{n}=\mathbf{1 3})$ & MMC $(\mathbf{n}=\mathbf{9 )}$ & Total \\
\hline $\mathrm{TaG} 1$ & $4(30.8 \%)$ & $3(33.3 \%)$ & $7(32.0 \%)$ \\
$\mathrm{TaG} 2$ & $1(7.7 \%)$ & $1(11.1 \%)$ & $2(9 \%)$ \\
$\mathrm{TaG} 3$ & - & $1(11.1 \%)$ & $1(4.5 \%)$ \\
$\mathrm{T} 1 \mathrm{G} 3$ & $8(61.5 \%)$ & $4(44.4 \%)$ & $12(54.5 \%)$ \\
$\mathrm{Total}$ & $13(100 \%)$ & $9(100 \%)$ & $22(100 \%)$ \\
\hline
\end{tabular}


For both agents, immediate treatment was shown to be more effective [14, 15]. Cases of our study were treated before the agreement on single-dose immediate postoperative treatment, so not all of our patients received single-dose chemotherapy.

Okamura et al compared the recurrence rates of $6-8$ weeks weekly BCG induction therapy and induction plus monthly maintenance therapy for NMIBC after TUR-BT. Single monthly administration of BCG as a maintenance therapy, after primary prophylaxis of 6 - 8 weeks, was found to be more effective in recurrence of $\operatorname{NMIBC}(\mathrm{P}=0.006)$ [16].

Krege et al conducted a randomized multi-centered study including 337 patients. All patients were TaT1 G1G3 bladder tumors. Patients with single TaG1 were excluded. Patients were randomized into groups to receive TUR-BT alone, TUR-BT plus intravesical MMC, and TUR-BT plus intravesical BCG. Statistical analyses revealed a clear advantage of intravesical agents over TUR-BT alone. Compared to TUR-BT alone group, relative risk was 0.508 and 0.618 for $\mathrm{MMC}$ and $\mathrm{BCG}$ groups, respectively. Progression rate was a mean of $4.22 \%$ per year for all groups [17]. Bohle et al published a meta-analysis concerning the comparison between adjuvant MMC and BCG on 9 studies and 1,328 cases. When recurrence risk was compared, there was a 46.4\% and 38.6\% risk for MMC and BCG groups, respectively. Outcome was statistically significant in advantage for BCG group $(\mathrm{P}=0.02)$ [18]. Similar to these findings, $\mathrm{BCG}$ group was advantageous over MMC group in our study.

It should not be forgotten that optimal dosage and duration for both intravesical chemotherapy and immunotherapy are not exactly proven. While the mechanism of immunotherapy depends on increasing the immunity by cellular defense, the major mechanism of chemotherapy is cellular damage for rapidly dividing cells. Therefore, chemotherapy acts on tumor cells directly, but immunotherapy acts on immune cells to activate them for abnormal tumor cells. Periodic activation of these immune mechanisms is crucial for optimum advantage in immunotherapy. For this reason, we used BCG therapy in a longer period, like the other studies approved for NMIBC.

Our study has some limitations such as relatively low patient numbers, its retrospective design and treatment heterogenities. There are no data about treatment complications. Even with those limitations, a clear advantage with $\mathrm{BCG}$ over MMC on progression can be recognized.

\section{Conclusions}

There is no consensus on what agent and what duration to install intravesically for patients with bladder tumors. We reported much better rates of recurrence for patients treated by BCG. Higher populations with prospective randomized studies need to back up our findings for this purpose.

\section{Conflict of Interest}

We certify that there is no conflict of interest with any financial organization regarding the material discussed in the manuscript.

\section{References}

1. Messing EM, Young TB, Hunt VB, Gilchrist KW, Newton MA, Bram LL, Hisgen WJ, et al. Comparison of bladder cancer outcome in men undergoing hematuria home screening versus those with standard clinical presentations. Urology. 1995;45(3):387-396; discussion 396-387.

2. Konety BR, Williams RD. Superficial transitional (Ta/T1/CIS) cell carcinoma of the bladder. BJU Int. 2004;94(1):18-21.

3. Sylvester RJ, van der Meijden AP, Oosterlinck W, Witjes JA, Bouffioux C, Denis L, Newling DW, et al. Predicting recurrence and progression in individual patients with stage Ta T1 bladder cancer using EORTC risk tables: a combined analysis of 2596 patients from seven EORTC trials. Eur Urol. 2006;49(3):466-465; discussion 475467.

4. Walsh PC, Retik AB, Vaughan ED, Wein AJ. Campbell Urology. 8th ed. Philedelphia Saunders co; p. 23722002.

5. Heney NM, Ahmed S, Flanagan MJ, Frable W, Corder MP, Hafermann MD, Hawkins IR. Superficial bladder cancer: progression and recurrence. J Urol. 1983;130(6):1083-1086.

6. Herr HW. Surgical factors in the treatment of superficial and invasive bladder cancer. Urol Clin North Am. 2005;32(2):157-164.

7. O'Donnell MA. Practical applications of intravesical chemotherapy and immunotherapy in high-risk patients with superficial bladder cancer. Urol Clin North Am. 2005;32(2):121-131.

8. Babjuk M, Burger M, Zigeuner R, Shariat S, Van Rhijn B, Comperat E, Sylvester R, Kaassinen E, Bohle A, Palou J, Roupret M. The updated EAU guidelines on non-muscle-invasive bladder cancer. Eur Urol. 2013.

9. Althausen AF, Prout GR, Jr., Daly JJ. Non-invasive papillary carcinoma of the bladder associated with carcinoma in situ. J Urol. 1976;116(5):575-580.

10. Oosterlinck W, Kurth KH, Schroder F, Bultinck J, Hammond B, Sylvester R. A prospective European Organization for Research and Treatment of Cancer Genitourinary Group randomized trial comparing transurethral resection followed by a single intravesical instillation of epirubicin or water in single stage Ta, T1 papillary carcinoma of the bladder. J Urol. 1993;149(4):749-752. 
11. Brosman SA. Experience with bacillus Calmette-Guerin in patients with superficial bladder carcinoma. J Urol. 1982;128(1):27-30.

12. Boccon-Gibod L, Leleu C, Herve JM, Belas M, Steg A. Bladder tumors invading the lamina propria (stage A/T1): influence of endovesical bacillus CalmetteGuerin therapy on recurrence and progression. Eur Urol. 1989;16(6):401-404.

13. Pansadoro V, Emiliozzi P, Defidio L, Donadio D, Florio A, Maurelli S, Lauretti S, et al. Bacillus CalmetteGuerin in the treatment of stage T1 grade 3 transitional cell carcinoma of the bladder: long-term results. J Urol. 1995;154(6):2054-2058.

14. Sylvester RJ, Oosterlinck W, van der Meijden AP. A single immediate postoperative instillation of chemotherapy decreases the risk of recurrence in patients with stage Ta T1 bladder cancer: a meta-analysis of published results of randomized clinical trials. J Urol. 2004;171(6 Pt 1):2186-2190, quiz 2435.
15. Beretta G. Bladder cancer. Mitomycin c. 2001. p170181.

16. Okamura T, Akita H, Ando R, Ikegami Y, Naiki T, Kawai N, Tozawa K, et al. Single monthly bacillus CalmetteGuerin intravesical instillation is effective maintenance therapy to prevent recurrence in Japanese patients with non-muscle-invasive bladder cancer. Int J Clin Oncol. 2012;17(5):477-481.

17. Krege S, Giani G, Meyer R, Otto T, Rubben H. A randomized multicenter trial of adjuvant therapy in superficial bladder cancer: transurethral resection only versus transurethral resection plus mitomycin $\mathrm{C}$ versus transurethral resection plus bacillus Calmette-Guerin. Participating Clinics. J Urol. 1996;156(3):962-966.

18. Bohle A, Jocham D, Bock PR. Intravesical bacillus Calmette-Guerin versus mitomycin $\mathrm{C}$ for superficial bladder cancer: a formal meta-analysis of comparative studies on recurrence and toxicity. J Urol. 2003;169(1):90-95. 